\title{
BMJ Open A cross-sectional study investigating the associations of person-organisation and person-group fit with staff outcomes in mental healthcare
}

Jessica Herkes, Louise A Ellis, ${ }^{\bullet}$ Kate Churruca, Jeffrey Braithwaite ${ }^{\odot}$

To cite: Herkes J, Ellis LA, Churruca $\mathrm{K}$, et al. A crosssectional study investigating the associations of personorganisation and person-group fit with staff outcomes in mental healthcare. BMJ Open 2019;9:e030669. doi:10.1136/ bmjopen-2019-030669

- Prepublication history and additional material for this paper are available online. To view these files, please visit the journal online (http://dx.doi org/10.1136/bmjopen-2019030669).

Received 03 April 2019 Revised 25 August 2019 Accepted 29 August 2019
Check for updates

(C) Author(s) (or their employer(s)) 2019. Re-use permitted under CC BY-NC. No commercial re-use. See rights and permissions. Published by BMJ.

Australian Institute of Health Innovation, Macquarie University, Sydney, New South Wales, Australia

Correspondence to

Jessica Herkes;

jess.herkes@mq.edu.au

\section{ABSTRACT}

Objectives Organisational and workplace cultures are fundamental determinants of health systems performance; through better understanding of the dimensions of culture there is the potential to influence them, and subsequently improve safety and quality of care, as well as the experiences of both patients and staff. One promising conceptual framework for studying culture in healthcare is person-environment $(\mathrm{P}-\mathrm{E})$ fit. Comprising personorganisational $(\mathrm{P}-\mathrm{O})$ and person-group $(\mathrm{P}-\mathrm{G})$ components, $\mathrm{P}-\mathrm{E}$ fit is defined as the extent to which individuals are compatible with their work environment. The aim of this study was to examine the associations of $P-0$ and $P-G$ fit with staff outcomes in mental healthcare.

Setting and participants Participants $(n=213)$ were staff and volunteers at 31 primary mental health facilities across six states of Australia.

Primary and secondary outcome measures Staff outcomes, comprising burnout (depersonalisation and emotional exhaustion), job satisfaction and work stress. Design A multidimensional survey tool was used to measure $\mathrm{P}-\mathrm{O}$ and $\mathrm{P}-\mathrm{G}$ fit, and staff outcomes. Multiple regression analyses were used to test the associations between fit and outcome measures.

Results The regression analyses indicated that, based on a Bonferroni adjusted alpha value of $\alpha=00417, \mathrm{P}-0$ fit accounted for $36.6 \%$ of the variability in satisfaction $(F=8.951, p \leq 0.001) ; 27.7 \%$ in emotional exhaustion $(F=6.766, p \leq 0.001) ; 32.8 \%$ in depersonalisation $(F=8.646$, $p \leq 0.001)$; and $23.5 \%$ in work stress $(F=5.439, p \leq 0.001)$. The $P-G$ fit results were less conclusive, with $P-G$ fit accounting for $15.8 \%$ of the variability in satisfaction $(F=4.184, p \leq 0.001) ; 10.0 \%$ in emotional exhaustion $(F=2.488, p=0.014) ; 28.6 \%$ in depersonalisation $(F=8.945$, $p \leq 0.001)$; and $10.4 \%$ in work stress ( $F=2.590, p=0.032$ ). There was no statistically significant increase in the variability accounted for when the interaction term of $\mathrm{P}-\mathrm{O}$ and $\mathrm{P}-\mathrm{G}$ fit was added to the regression.

Conclusions The findings highlight that staff's perception of their workplace and organisational culture can have implications for staff well-being.

\section{INTRODUCTION}

Amidst growing interest in organisational and workplace cultures in healthcare contexts, there is increased understanding of the

\section{Strengths and limitations of this study}

- Participation from a broad cross-section of staff from 31 mental health facilities across six states in Australia.

- Survey was developed and validated based on an extensive literature review and existing validated tools where possible.

- Small sample size limits the generalisability of the study conclusions; some of the analyses did not reach significance, but replications with larger samples may rectify this.

potential downstream effects of culture on outcomes for both staff (eg, well-being, work-life balance, burnout) and patients (eg, quality of care, mortality, disability). ${ }^{1-3}$ The focus on culture in healthcare is particularly important as clinicians have disproportionately high rates of suicidal ideation, depression and burnout compared with other professions. ${ }^{4-11}$ Such experiences are not only harmful to clinicians personally, but may have effects on patient care through, for example, decreased staff productivity, ${ }^{5}$ and increased risk of medical errors. ${ }^{12} 13$ Organisational culture is understudied across healthcare compared with other industries. ${ }^{14}$ This is particularly concerning in mental health services as individuals working in these settings may be influenced more by localised culture than individuals in other types of health facilities, due to the importance of human relationships in the intense personalisation and continuity of care demanded for treating mental illnesses. ${ }^{15}$ Further research into organisational and workplace cultures may be important in explaining this phenomenon, and facilitating effective culture change interventions within healthcare contexts. ${ }^{5}$

\section{Person-environment fit}

In an effort to understand what it means to fit in with the culture of a workplace group 
or organisation, researchers have proposed the theory of person-environment (P-E) fit. P-E fit is mobilised to understand an individual's compatibility with a component of their work environment, which can occur if: (1) one or both entities, that is, the environment and the worker, fulfil the other's needs; and/or (2) each entity has similar characteristics. ${ }^{16}$ P-E fit comprises several distinct measures of environmental interaction, including person-job, person-supervisor, person-group (P-G) and person-organisation (P-O) fit. ${ }^{17} 18$ The latter two, P-G and P-O fit, are particularly relevant here as they effectively refer to fit with workplace and organisational cultures, respectively. Within past fit research in healthcare settings, the trend across the included studies is that staff perceptions of compatibility with the work group $(\mathrm{P}-\mathrm{G})^{19-21}$ or organisation $(\mathrm{P}-\mathrm{O})^{22-30}$ are conducive to better staff outcomes.

Just as workplace subcultures and the broader organisational cultures are thought to interact, ${ }^{2}$ it is reasonable to expect that P-O fit and P-G fit interact. ${ }^{31}$ It is beneficial to investigate multiple measures of the environment simultaneously, as they are never experienced in isolation and may have the capacity to interrelate. ${ }^{32-34}$ Indeed, a number of studies have investigated both P-O and P-G fit in healthcare settings (but not in the context of mental healthcare), finding a significant association with job satisfaction and turnover intent. ${ }^{14} 1920$ Additionally, only one study has investigated the potential interaction between P-O and P-G fit, which postulated that high P-G fit may help to temper the negative effects of low P-O fit (eg, where an individual's vision does not align with those of the organisation, but they are motivated by their coworkers). This study found no evidence for an interaction, which was attributed to methodological limitations such as only measuring certain components of P-O and P-G fit (see definitions in Components of fit section, below). ${ }^{32}$ This points to further research being necessary in healthcare, and specifically in mental healthcare settings, to examine the relationships between $\mathrm{P}-\mathrm{O}$ and P-G fit taking a holistic view of the environment, by using both P-O and P-G fit measures to develop a more rigorous survey procedure than previously accomplished. ${ }^{1633}$

\section{Components of fit}

Adding to the richness of fit theory and its potentially complex manifestation in healthcare, P-E fit researchers delineate multiple components of fit. These components can be described as characteristic ways that an individual experiences fit with their workplace or organisation (eg, supplementary, complementary, needs-supplies and demands-abilities fit). ${ }^{16}{ }^{18}$ Supplementary fit, the most commonly studied component, is defined as the congruence between the individual and the environment, such as through sharing similar values, goals or 'personality'. ${ }^{35}$ Complementary fit is the converse, and describes a type of fit in which the individual or their workplace or organisation fills a gap in, adds something unique to or 'makes whole' the other. ${ }^{35-37}$
Two additional components, needs-supplies (where the individual's requirements, eg, for further training, are fulfilled by the environment ${ }^{1638}$ ) and demands-abilities (where the individual has the required capability and capacity to meet environmental requests ${ }^{1639}$ ) are studied less frequently, both within and outside healthcare. An individual may experience parts of each of these four components, contributing to the culminating feeling of 'fitting in' with the environment. However, no currently available survey tools comprehensively measure the components of P-O and P-G fit. This may limit the conclusions drawn with regard to the influence of fit, and particular components of fit, on staff outcomes in healthcare.

\section{Fit in the workplace}

A multitude of staff outcomes have been examined within past research in health settings. Staff burnout has been well studied in mental health settings due to its high prevalence and relationship with other important outcomes like staff retention. ${ }^{4-42}$ However, there is a lack of information on the relationship between burnout and P-O or P-G fit, particularly the different components of burnout including emotional exhaustion, depersonalisation and personal accomplishment. ${ }^{22} 234344$ There is also less known about the relationship of $\mathrm{P}-\mathrm{O}$ and $\mathrm{P}-\mathrm{G}$ fit to job satisfaction and work stress in mental healthcare. Regardless of the dearth of studies on these outcomes, it was postulated that $\mathrm{P}-\mathrm{O}$ and $\mathrm{P}-\mathrm{G}$ fit might have importance given their associations with organisational and workplace cultures. ${ }^{45}$ That is, past studies have found relationships between organisational and workplace cultures and staff outcomes, with the implication that fostering a healthy culture at work may be protective against the kinds of negative staff outcomes that are common in stressful vocations, ${ }^{2022-264647}$ such as those found in mental health settings.

Against this background, the aim of the current study was to examine the associations between P-O and P-G and staff outcomes, including job satisfaction, burnout and work stress, in the context of mental healthcare. Based on this aim and the studies discussed, the following research questions $(\mathrm{RQ})$ were developed:

RQ1: What is the association between P-O fit and staff outcomes, including satisfaction (RQ1a), work stress (RQ1b) and burnout, comprising emotional exhaustion (RQ1c) and depersonalisation (RQ1d)?

RQ2: What is the association between P-G fit and staff outcomes, including satisfaction (RQ2a), work stress (RQ2b) and burnout, comprising emotional exhaustion (RQ2c) and depersonalisation (RQ2d)?

RQ3: Is a significant proportion of the variance in staff outcomes, including satisfaction (RQ3a), work stress (RQ3b) and burnout, comprising emotional exhaustion (RQ3c) and depersonalisation (RQ3d), accounted for by the interaction between the components of $\mathrm{P}-\mathrm{O}$ and $\mathrm{P}-\mathrm{G}$ fit? 


\section{METHODS}

\section{Study setting and participants}

The study was conducted in Australian community-based mental health facilities run by headspace. Headspace is a national mental health organisation comprising clinical, managerial and administrative staff that aims to provide early intervention mental health services for young people aged 12-25 years old. ${ }^{48}$ All 97 headspace centres in Australia were invited to participate, and 31 headspace centres across six states were involved as research sites. All staff, students and volunteers from participating headspace centres $(n=640)$ were invited to take part in the online survey via email in May 2017. Both clinical and non-clinical staff were eligible as they are all employees, and hence all contribute to work culture. Volunteers and students were eligible to participate based on evidence that low P-O and P-G fit make them more susceptible to outcomes such as burnout and turnover intent, ${ }^{49}$ similar to employees. ${ }^{22} 2441$ A reminder email was sent out 2 weeks after the initial invitation, and the survey closed in July 2017. Based on the recommendations of commonly accepted rules-of-thumb for statistical analysis, ${ }^{50-53}$ a minimum sample size of 120 participants was required for adequate statistical analyses. ${ }^{50-53}$

\section{Patient and public involvement}

There were no funds or time allocated for patient and public involvement so we were unable to involve patients in this study. However, we have disseminated a plain language summary of our results to the public involved in the research and their organisations.

\section{Survey measures}

\section{Overall survey}

The final survey consisted of 75 items including five demographic questions, 21 questions measuring each of the components of P-O and P-G fit, and 28 outcome items. All items were rated on Likert-type scales.

\section{$\mathrm{P}-0$ and $\mathrm{P}-\mathrm{G}$ fit}

Following an extensive literature review, a list of items was generated to measure each of the hypothesised components of P-O and P-G fit; some items were adapted from existing questionnaires and others were freshly formulated for the study (see online supplementary appendix 1 for specific sources)..$^{343555}$ Items were piloted with a group of experienced researchers $(n=5)$ to test for possible misinterpretations of questions, instructions and response format. Minor adjustments were made to the final version of the survey. More information about the process of validating the survey can be found in a separate forthcoming article.

\section{Staff outcomes}

Existing validated scales were selected to measure job satisfaction, burnout and work stress. Three items in the Job Satisfaction section of the Job Diagnostic Survey were used, and the remaining two items, which asked about the individual's perception of the satisfaction of 'most people', were excluded to prevent confounding of results with perceptions of the fit of other coworkers. ${ }^{56}$ Good internal consistency for job satisfaction was found for the current sample (Cronbach's alpha $=0.85) .{ }^{57}$ Burnout was measured through a 10-item version of the Maslach Burnout Inventory ${ }^{43} 4458$; this has been frequently used in health settings. ${ }^{59} 60$ Only two subscales of burnoutemotional exhaustion and depersonalisation-were included in the current survey because the third component (personal accomplishment) is less applicable to non-clinical staff. For the current sample, good internal consistency was found for the emotional exhaustion and depersonalisation subscales (Cronbach's alpha $=0.92$ and 0.87 , respectively). ${ }^{61}$ An adapted version of the General Health Questionnaire-12 was used to measure work stress, with only one alteration ('many things stressful' was replaced by 'stressful' as it was deemed confusing in the context of this survey). ${ }^{62} 63$ The internal consistency for work stress for the present sample was excellent (Cronbach's alpha $=0.91$ ).

\section{Data analysis}

Analysis of measurement instruments

Following missing data imputation using the expectation maximisation algorithm to provide maximum likelihood estimates in IBM SPSS V.24 ${ }^{64}$ data were imported into the LISREL pre-processor (PRELIS) and confirmatory factor analyses (CFAs) were conducted using LISREL V.9.30 to validate the $\mathrm{P}-\mathrm{O}$ and $\mathrm{P}-\mathrm{G}$ fit surveys. ${ }^{65}$ The final survey items and further details about the process of CFAs can be seen in the online supplementary appendix 2 .

\section{Analysis of the relationship between fit and staff outcomes}

To examine RQ1-RQ3, hierarchical multiple regression analyses (MRAs) were conducted, allowing the independent variability accounted for on each step of the regression to be analysed. Thus, the variability of fit (entered on step 2) could be measured over that accounted for by demographic characteristics of age, gender, role and time at centre (entered on step 1), which have been previously theoretically justified. ${ }^{24} 283349$ Assumptions of MRA (normality, multicollinearity, outliers, linearity and homoscedasticity) were tested prior to the analyses, and data pruning occurred in line with accepted practice. ${ }^{536667}$ Composite (mean) scales ${ }^{68}$ were then computed for each fit component included from the final CFA models. To test RQ3, interaction terms were produced between the product of the variables in question (P-O and P-G fit), and these were centred to avoid multicollinearity. ${ }^{5369}$ This ensured that the test would measure if the interaction accounted for a significant proportion of variance above that of the variability of each fit component separately.

To account for the inflated familywise error caused by computing multiple tests, the Bonferroni post hoc adjustment was made. ${ }^{70}$ Based on the 12 tests conducted with this data, the new alpha value for each test was $\alpha=00417$. However, due to the conservative nature of the Bonferroni adjustment, significance was considered in relation 
to both adjusted $\alpha=0.00417$ and non-adjusted $\alpha=.05$ alpha values. $^{71} 72$

\section{RESULTS}

\section{Demographics}

Participants ( $\mathrm{n}=194,30.3 \%$ response rate) were $77.8 \%$ $(\mathrm{n}=151)$ female. Respondents had been employed at their mental health facility for a variety of lengths, from less than a month $(2.3 \%)$ to over 5 years $(8.9 \%)$. Respondents were most commonly aged between 30 and 39 years old $(32.1 \% ; n=63)$, but the age range of the sample varied from 18 to over 60 years old. The average number of respondents from each headspace centre was 5.8 (range 1-22; $\mathrm{SD}=4.95$ ). For more details, see online supplementary appendix 1 .

\section{Multiple regression analysis}

For RQ1 and RQ2, hierarchical MRAs allowed prediction of the incremental contribution of the fit components beyond the variance accounted for by demographic characteristics. ${ }^{667}$ For each hierarchical MRA, step 1 consisted of demographics. In step 1 of the hierarchical MRA, the demographics collectively accounted for a non-significant $3.9 \%$ of the variability in satisfaction $\left(R^{2}=0.039, F\right.$ $(4,183)=1.846, p=0.12) ; 6.7 \%$ in emotional exhaustion $\left(\mathrm{R}^{2}=0.067, \mathrm{~F}(4,183)=1.411, \mathrm{p}=0.23\right) ; 6.7 \%$ in depersonalisation $\left(\mathrm{R}^{2}=0.067, \mathrm{~F}(4,183)=3.264, \mathrm{p}=0.01\right)$; and $4.2 \%$ in work stress $\left(\mathrm{R}^{2}=0.042, \mathrm{~F}(4,183)=1.998, \mathrm{p}=0.09\right)$. In step 2 , the fit data were added to the regression model (online supplementary appendix 3 ).

The association of P-0 fit and staff outcomes

The P-O fit measures (value, goal and personality congruence, complementary, needs-supplies and demands-abilities fit) were added at step 2 of each of the four regression analyses, and accounted for a statistically significant increase in the variability accounted for by the model in all four outcomes (see table 1). Thus, RQ1 was answered (including RQ1a, RQ1b, RQ1c and RQ1d). There were differential results in regards to the relationship of each outcome to the components of P-O fit (see online supplementary appendix 3). The results indicated that needs-supplies fit was the only individual P-O fit component that accounted for a significant proportion of the variance in the staff outcomes of satisfaction $(p<0.001)$, emotional exhaustion $(p=0.001)$ and work stress $(p<0.001)$. None of the other fit components individually accounted for a significant proportion of the variance, yet cumulatively they had a significant association with staff outcomes.

\section{The association of P-G fit and staff outcomes}

RQ2 was addressed with the same methods as for RQ1, but with the four P-G fit components added in step 2 of the regression. Here, the results (table 1) suggested that a significant proportion of the variance accounted for in job satisfaction (RQ2a) and depersonalisation (RQ2d), but this association was not significant for emotional

Table 1 Proportion of variance of outcome measures accounted for by P-O fit measures, P-G fit measures and the interaction between P-O and P-G fit

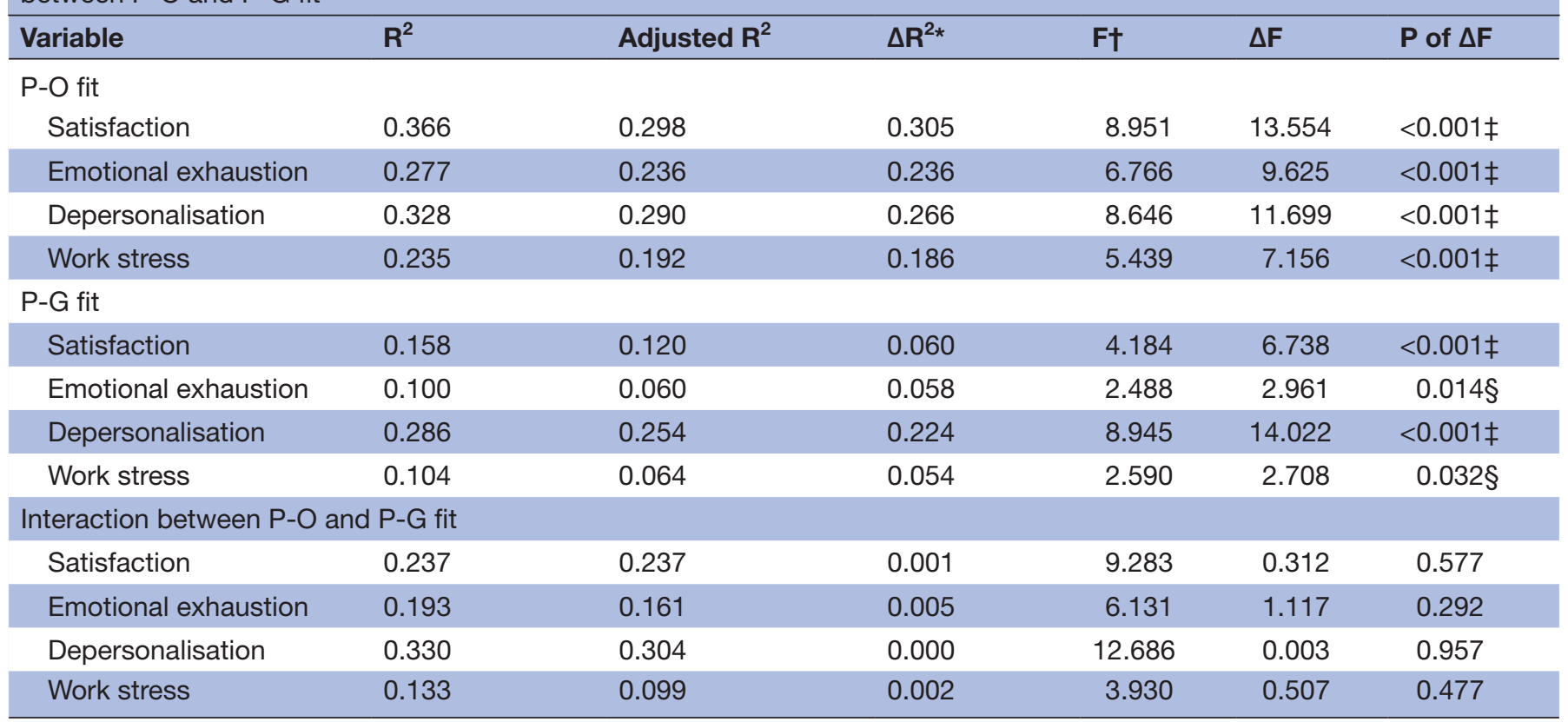

Interaction between $\mathrm{P}-\mathrm{O}$ and $\mathrm{P}-\mathrm{G}$ fit is adjusted for age, gender, time and role at centre.

${ }^{*} \Delta R^{2}$ based on change in the $R^{2}$ from Sstep 1 of the multiple regression analysis.

$\dagger F$ value based on Sstep 2 of the hierarchical multiple regression analysis.

$\ddagger$ Significant at $\alpha=0.00417$ after Bonferroni adjustment.

$\S$ Significant at $\alpha=0.05$.

$\mathrm{P}-\mathrm{G}$, person-group; P-O, person-organisational. 
exhaustion (RQ2c) or work stress (RQ2b). However, if the Bonferroni adjustment was not considered, P-G fit accounted for significant variation in all outcome measures. The only significant individual component of fit was goal congruence, which significantly accounted for a proportion of the variance in depersonalisation $(p=0.004)$ (online supplementary appendix 3$)$.

\section{Testing for the interaction between $\mathrm{P}-0$ and $\mathrm{P}-\mathrm{G}$ fit}

Three-step hierarchical MRAs tested whether there was an interaction between P-O and P-G fit that influenced the relationship between $\mathrm{P}-\mathrm{O}$ fit and the outcome variables. Demographic statistics were entered into step 1 , the main effects of P-O and P-G fit were entered on step 2, and the interaction product term $(\mathrm{P}-\mathrm{O} \times \mathrm{P}-\mathrm{G})$ was entered on step 3 . This simplified interaction term was appropriate due to the exploratory nature of the study.

Step 1 of the hierarchical MRA suggested that demographics accounted for a non-significant proportion of variability. In step 2, the mean P-O fit and P-G fit scores were added to the regression equation. The addition of P-O and P-G mean scores accounted for $23.7 \%$ of the variance in satisfaction $\left(\mathrm{R}^{2}=0.237, \mathrm{~F}(7,180)=9.283\right.$, $\mathrm{p}<0.001) ; 19.3 \%$ in emotional exhaustion $\left(\mathrm{R}^{2}=0.193\right.$, $\mathrm{F}(7,180)=6.131, \mathrm{p}<0.001) ; 33.0 \%$ in depersonalisation $\left(\mathrm{R}^{2}=0.330, \mathrm{~F} \quad(7,180)=12.686, \mathrm{p}<0.001\right)$; and $13.3 \%$ in work stress $\left(\mathrm{R}^{2}=0.133, \mathrm{~F}(7,180)=3.930, \mathrm{p}=0.001\right)$. There was no statistically significant increase in the amount of variability accounted for in any of the outcome measures (RQ3, including RQ3a, RQ3b, RQ3c, and RQ3d) when the interaction term was added to the model (step 3; table 1). Additionally, none of the components of fit individually accounted for a significant proportion of variance in any of the staff outcomes (online supplementary appendix 3 ).

\section{DISCUSSION}

This study offers new insights into the conceptualisation of $\mathrm{P}-\mathrm{O}$ and P-G fit, and their associations with staff outcomes in the context of mental healthcare, adding richness to the current research landscape. The results suggest the important influence of fit perceptions on staff outcomes within mental healthcare, a notably challenging working environment. Below, each of the results of the MRAs is discussed in turn.

As expected from previous literature, there was a significant association of P-O fit with all four of the staff outcome variables. ${ }^{22} 232526464773$ Moreover, the significant variance accounted for by the individual component of P-O fit, needs-supplies, with the outcomes of satisfaction, emotional exhaustion and work stress, indicates the importance of staff working in mental health facilities feeling valued, validated and recognised at work. These findings highlight the importance of measuring multiple components of fit, first identified in 1996, but still rarely studied. ${ }^{16}$ By extension, this suggests the importance of organisational culture in fostering a welcoming, healthy work environment to allow individuals to feel this sense of fit. By measuring individual components of fit, this study was able to determine the unique importance of needs-supplies fit for staff working in mental healthcare, and yet needs-supplies fit is rarely studied in P-O fit research.

The pattern of results from the P-G MRA, whereby only two of the staff outcomes were significantly associated with P-G fit, raises various questions regarding the conceptualisations of $\mathrm{P}-\mathrm{G}$ fit. The non-significant associations of P-G fit with emotional exhaustion and work stress may be attributed to limitations in the survey used for the study, for example, due to the limited range of values used to measure work stress. Another potential issue is the extent to which each aspect of burnout is appropriate to assess in both clinical and non-clinical staff, as was the case in this study. However, the other measured component of burnout, depersonalisation, was significantly associated with P-G. Hence, these results provide some evidence supporting the importance of workplace culture in promoting P-G fit, which may improve some staff outcomes.

Consistent with the results of Vogel $e t a l,{ }^{32}$ there was no significant interaction between $\mathrm{P}-\mathrm{O}$ and $\mathrm{P}-\mathrm{G}$ fit beyond that accounted for by the main effects and demographic characteristics. This lack of interaction manifested despite previous theoretically based arguments that suggest healthcare is to a considerable extent composed of differentiated, and oftentimes fragmentary cultures (eg, in terms of distinctive work areas or professional groupings). There are previous suggestions that these subcultures (measured through P-G fit), may be of more importance for staff outcomes than P-O fit. ${ }^{23} 32$ It is possible that the perception of fitting in with one's work group and organisation do not interact in the context of mental healthcare, but to the contrary qualitative research suggests they do interact. ${ }^{74}$

\section{Research implications}

The results of this study have implications for practical approaches to perceiving fit at work. Ultimately, this work has the potential to influence the way work culture as a whole is understood, identified and measured. The results could be applied to culture change interventions, and particularly improvements to staff well-being at work. For example, the results suggest P-O and P-G fit may be important in understanding how mental health staff experience their workplace and organisation. This can be particularly beneficial in understanding the factors contributing to burnout and work stress. Following further research to unpack and understand these concepts and their relationships in practice, these results might contribute to the design of new interventions to improve staff workplace experience, thereby potentially improving staff outcomes.

\section{Strengths and limitations}

A larger sample size and more participants at each research site may have been beneficial, and perhaps 
across multiple healthcare settings, to elucidate further the trends in the relationship of P-O and P-G fit to staff outcomes, and the size and extent of any interactions. It would have also been useful to further analyse the effect of responder demographics on results, as it was a potential source of bias in this study. Additionally, exploring the theoretical basis of potential interactions could be useful for future studies.

\section{CONCLUSION}

This study provided key information by which to understand how fit is associated with staff outcomes in mental healthcare. It offers a new approach, and provides a stepping-stone for future research in P-O fit, P-G fit and organisational and workplace cultures, and the application of this paradigm to healthcare contexts. Although further research would be prudent in order to verify the extent to which interactions between P-O and P-G fit prevail, the results as they stand contribute a fresh understanding of the importance of the association between the components of fit and staff outcomes.

Contributors $\mathrm{JH}$ conceptualised and drafted the manuscript, in conjunction with $\mathrm{KC}$ and LAE for support with statistical analysis. KC, LAE and JB edited the manuscript and critically reviewed its intellectual content. All authors approved the final version of the manuscript.

Funding $\mathrm{JH}$ was funded by a Research Training Program Master of Research (RTPMRES) stipend scholarship at Macquarie University. JB is supported by multiple NHMRC grants.

Competing interests None declared.

Patient consent for publication Not required.

Ethics approval Survey participants were involved in this research, with approval from Macquarie University HREC (5201700241) and Alfred Hospital (Melbourne) Ethics Committee (project 198/17), and informed consent from each participant. No patients were involved in the research.

Provenance and peer review Not commissioned; externally peer reviewed.

Data availability statement Data relevant to the study are included in the article or uploaded as supplementary information. Further data supporting the confirmatory factor analyses findings of this study are available from the corresponding author, JH, upon request.

Open access This is an open access article distributed in accordance with the Creative Commons Attribution Non Commercial (CC BY-NC 4.0) license, which permits others to distribute, remix, adapt, build upon this work non-commercially, and license their derivative works on different terms, provided the original work is properly cited, appropriate credit is given, any changes made indicated, and the use is non-commercial. See: http://creativecommons.org/licenses/by-nc/4.0/.

\section{REFERENCES}

1. Parmelli E, Flodgren G, Beyer F, et al. The effectiveness of strategies to change organisational culture to improve healthcare performance: a systematic review. Implement Sci 2011;6:1-8.

2. Braithwaite J, Hyde P, Pope C. Culture and Climate in Health Care Organizations. Basingstoke, London: Palgrave Macmillan, 2010and.

3. Braithwaite J, Herkes J, Ludlow K, et al. Association between organisational and workplace cultures, and patient outcomes: systematic review. BMJ Open 2017;7:e017708.

4. Balch CM, Shanafelt T. Combating stress and burnout in surgical practice: a review. Adv Surg 2010;44:29-47.

5. Balch CM, Copeland E. Stress and burnout among surgical oncologists: a call for personal wellness and a supportive workplace environment. Ann Surg Oncol 2007;14:3029-32.
6. Jenkins KD. Keeping the doctor healthy: ongoing challenges. Med J Aust 2009;191.

7. Felps W, Mitchell TR, Byington E. How, when, and why bad apples spoil the barrel: negative group members and dysfunctional groups. Res Organ Behav 2006;27:175-222.

8. Cole TR, Nathan C. The art of medicine: the suffering of physicians. Lancet 2009;374:1414-5.

9. Eneroth M, Gustafsson Sendén M, Løvseth LT, et al. A comparison of risk and protective factors related to suicide ideation among residents and specialists in academic medicine. BMC Public Health 2014;14:271.

10. Center $\mathrm{C}$, Davis $\mathrm{M}$, Detre $\mathrm{T}$, et al. Confronting depression and suicide in physicians: a consensus statement. JAMA 2003;289:3161-6.

11. Schernhammer $E$. Taking their own lives -- the high rate of physician suicide. N Engl J Med 2005;352:2473-6.

12. Shanafelt TD, Balch CM, Bechamps G, et al. Burnout and medical errors among American surgeons. Ann Surg 2010;251:995-1000.

13. Fahrenkopf AM, Sectish TC, Barger LK, et al. Rates of medication errors among depressed and burnt out residents: prospective cohort study. BMJ 2008;336:488-91.

14. Herkes J, Churruca K, Ellis LA, et al. How people fit in at work: systematic review of the association between person-organisation and person-group fit with staff outcomes in healthcare. BMJ Open 2019;9:e026266.

15. Morris A, Bloom JR, Kang S. Organizational and individual factors affecting consumer outcomes of care in mental health services. Adm Policy Ment Health 2007;34:243-53.

16. Kristof AMYL. Person-organization fit: an integrative review of its conceptualizations, measurement, and implications. Pers Psychol 1996;49:1-49.

17. Schneider B. Fits about fit. Appl Psychol 2001;50:141-52.

18. Kristof-Brown A, Guay R. Person-environment fit, in APA Handbook of Industrial and Organizational Psychology: Maintaining, Expanding, and Contracting the Organization. In: Zedeck S, ed. American psychological association, 2011: 3-50.

19. Dotson MJ, Dave DS, Cazier JA, et al. An empirical analysis of nurse retention. J Nurs Adm 2014;44:111-6.

20. Findik $M$, Öğüt $A$, Çağliyan V. An evaluation about personorganization fit, job satisfaction, and turnover intention: a case of health institution. Mediterr J Soc Sci 2013;4:434-40.

21. Verplanken $B$. Value congruence and job satisfaction among nurses: a human relations perspective. Int J Nurs Stud 2004;41:599-605.

22. Leiter MP, Frank E, Matheson TJ. Demands, values, and burnout: relevance for physicians. Can Fam Physician 2009;55:1224-6.

23. Leiter MP, Gascón S, Martínez-Jarreta B. Making sense of work life: a structural model of burnout. J App/ Soc Psychol 2010;40:57-75.

24. Leiter MP, Jackson NJ, Shaughnessy K. Contrasting burnout, turnover intention, control, value congruence and knowledge sharing between baby boomers and generation X. J Nurs Manag 2009;17:100-9.

25. Leiter MP, Day A, Price L. Attachment styles at work: measurement, collegial relationships, and burnout. Burn Res 2015;2:25-35.

26. Leiter MP. A two process model of burnout and work engagement: distinct implications of demands and values. G Ital Med Lav Ergon 2008;30(1 Suppl A):A52-A58.

27. Bao Y, Vedina R, Moodie S, et al. The relationship between value incongruence and individual and organizational well-being outcomes: an exploratory study among Catalan nurses. J Adv Nurs 2013;69:631-41.

28. Zhang $\mathrm{M}$, Yan $\mathrm{F}$, Wang $\mathrm{W}$, et al. Is the effect of person-organisation fit on turnover intention mediated by job satisfaction? A survey of community health workers in China. BMJ Open 2017;7:e013872.

29. Schmidt K-H. The relation of goal incongruence and self-control demands to indicators of job strain among elderly care nursing staff: a cross-sectional survey study combined with longitudinally assessed absence measures. Int J Nurs Stud 2010;47:855-63.

30. Bellou V. Matching individuals and organizations: evidence from the Greek public sector. Employee Relations 2009;31:455-70.

31. Edwards J, Billsberry J. Testing a multidimensional theory of personenvironment fit. J Manage Issues 2010;22:476-93.

32. Vogel RM, Feldman DC. Integrating the levels of person-environment fit: the roles of vocational fit and group fit. $J$ Vocat Behav 2009;75:68-81.

33. Chuang A, Shen C-T, Judge TA. Development of a multidimensional instrument of person-environment fit: the perceived PersonEnvironment fit scale (PPEFS). Appl Psychol 2016;65:66-98

34. Cable DM, DeRue DS. The convergent and discriminant validity of subjective fit perceptions. J Appl Psychol 2002;87:875-84.

35. Piasentin KA, Chapman DS. Subjective person-organization fit: bridging the gap between conceptualization and measurement. $J$ Vocat Behav 2006;69:202-21. 
36. Piasentin KA, Chapman DS. Perceived similarity and complementarity as predictors of subjective person-organization fit. J Occup Organ Psychol 2007;80:341-54

37. Santos LBdos, De Domenico SMR. Person-organization fit: bibliometric study and research agenda. European Business Review 2015;27:573-92.

38. Yu KYT, Davis HM. Autonomy's impact on newcomer proactive behaviour and socialization: a needs-supplies fit perspective. $J$ Occup Organ Psychol 2016;89:172-97.

39. Supeli $A$, Creed $P$. The incremental validity of perceived goal congruence: the assessment of person-organization fit. J Career Assess 2014;22:28-42.

40. Prosser D, Johnson S, Kuipers E, et al. Mental health, "burnout" and job satisfaction in a longitudinal study of mental health staff. Soc Psychiatry Psychiatr Epidemiol 1999;34:295-300.

41. Fong TCT, Ho RTH, Au-Yeung FSW, et al. The relationships of change in work climate with changes in burnout and depression: a 2-year longitudinal study of Chinese mental health care workers. Psychol Health Med 2016;21:401-12.

42. Edwards D, Burnard P, Coyle D, et al. Stress and burnout in community mental health nursing: a review of the literature. $J$ Psychiatr Ment Health Nurs 2000;7:7-14.

43. Maslach C, Schaufeli WB, Leiter MP. Job burnout. Annu Rev Psychol 2001;52:397-422.

44. Schaufeli W, Enzmann D, Girault NSchaufeli WB, Maslach C, Marek T, eds. Measurement of burnout: a review, in Professional Burnout: Recent Developments in Theory and Research. Washington, USA: Taylor \& Francis, 1993: 199-215.

45. Montgomery A, Todorova I, Baban A, et al. Improving quality and safety in the hospital: the link between organizational culture burnout, and quality of care. Br J Health Psychol 2013;18:656-62.

46. Gregory ST, Menser T. Burnout among primary care physicians: a test of the areas of worklife model. J Healthc Manag 2015;60:133-48.

47. Risman KL, Erickson RJ, Diefendorff JM. The impact of personorganization fit on nurse job satisfaction and patient care quality. Appl Nurs Res 2016;31:121-5.

48. Hilferty Fet al. Is Headspace Making a Difference to Young People's Lives? Final Report of the Independent Evaluation of the Headspace Program. Social Policy Research Centre, UNSW Australia: Sydney, 2015.

49. Scherer LL, Allen JA, Harp ER. Grin and bear it: An examination of volunteers' fit with their organization, burnout and spirituality. Burn Res 2016;3:1-10.

50. Kline P. An Easy Guide to Factor Analysis. New York, NY: Routledge, 1994.

51. Green SB. How many subjects does it take to do a regression analysis. Multivariate Behav Res 1991;26:499-510.

52. Schmidt FL. The relative efficiency of regression and simple unit predictor weights in applied differential psychology. Educ Psychol Meas 1971;31:699-714.

53. Hills A. Foolproof Guide to Statistics using IBM SPSS. In: . Sydney, Australia: Pearson Australia, 2011.
54. Cooman Ret al. Creating inclusive teams through perceptions of supplementary and complementary person-team fit: examining the relationship between person-team fit and team effectiveness. Group Organ Manage 2016;41:310-42.

55. Seong Jet al. Person-group fit: diversity antecedents, proximal outcomes, and performance at the group level. J Manag 2015;41:1184-213.

56. Bowling NA, Hammond GD. A meta-analytic examination of the construct validity of the Michigan organizational assessment questionnaire job satisfaction Subscale. J Vocat Behav 2008;73:63-77

57. Tavakol M, Dennick R. Making sense of Cronbach's alpha. Int J Med Educ 2011;2:53-5.

58. Maslach $\mathrm{C}$, Jackson SE. The measurement of experienced burnout. J Organ Behav 1981;2:99-113.

59. Schaufeli WB, Bakker AB, Hoogduin K, et al. On the clinical validity of the maslach burnout inventory and the burnout measure. Psychol Health 2001;16:565-82.

60. Kilroy Aet al. Perceptions of high-involvement work practices, person-organization fit, and burnout: a time-lagged study of health care employees. Hum Resour Manage 2016:1-15.

61. Bland JM, Altman DG. Statistics notes: Cronbach's alpha. BMJ 1997;314:572.

62. Golderberg D, Williams P. A User's Guide to the General Health Questionnaire. Windsor, UK: NFER-Nelson, 1988.

63. Prosser D, Johnson S, Kuipers E, et al. Mental health, "burnout' and job satisfaction among hospital and community-based mental health staff. Br J Psychiatry 1996;169:334-7.

64. IBM SPSS Statistics for Windows. Armonk, NY IBM Corp; 2016.

65. Scientific Software International. lisrel-Scientific software international. IL: Skokie, 2019.

66. Field A. Discovering Statistics using IBM SPSS Statistics. Dubai, India: SAGE Publications Ltd, 2009.

67. Allen P, Bennett K. PASW statistics by SPSS: a practical guide version 18.0. Victoria, Australia: CENGAGE Learning., 2010.

68. Roni SM. Introduction to SPSS. Joondalup, Australia: SOAR Centre, Graduate Research School of Business, Edith Cowan University, 2014.

69. Tabachnick BG, Fidell LS. Using multivariate statistics. USA: Pearson Education, 2007.

70. Bland JM, Altman DG. Multiple significance tests: the Bonferroni method. BMJ 1995;310.

71. Perneger TV. What's wrong with Bonferroni adjustments. BMJ 1998;316:1236-8.

72. Feise RJ. Do multiple outcome measures require $p$-value adjustment? BMC Med Res Methodol 2002;2:8.

73. Hatton $\mathrm{C}$, Rivers $\mathrm{M}$, Mason $\mathrm{H}$, et al. Organizational culture and staff outcomes in services for people with intellectual disabilities. $J$ Intellect Disabil Res 1999;43:206-18.

74. Herkes Jet al. Coordinating care across boundaries in mental health facilities: a qualitative approach to understanding perceptions of fit at work. In: Organ Behav Health Care. Canada: Montreal, 2018. 